\title{
MAXIMAL AND SINGULAR INTEGRAL OPERATORS AND THEIR COMMUTATORS ON GENERALIZED WEIGHTED MORREY SPACES WITH VARIABLE EXPONENT
}

\author{
VAgif S. GUliyev, JAVANShir J. HASANOV AND XAYYAM A. BADAlOV
}

Abstract. We consider the generalized weighted Morrey spaces $\mathscr{M}_{\omega}^{p(\cdot), \varphi}(\Omega)$ with variable exponent $p(x)$ and a general function $\varphi(x, r)$ defining the Morrey-type norm. In case of unbounded sets $\Omega \subset \mathbb{R}^{n}$ we prove the boundedness of the Hardy-Littlewood maximal operator and Calderón-Zygmund singular operators with standard kernel, in such spaces. We also prove the boundedness of the commutators of maximal operator and Calderón-Zygmund singular operators in the generalized weighted Morrey spaces with variable exponent

Mathematics subject classification (2010): 42B20, 42B25, 42B35.

Keywords and phrases: Maximal operator, singular integral operators, generalized weighted Morrey space with variable exponent, BMO space.

\section{REFERENCES}

[1] D. R. AdAms, A note on Riesz potentials, Duke Math. 42 (1975), 765-778.

[2] M. AgCayazi, A. GogatishVili, K. Koca, And R. Mustafayev, A note on maximal commutators and commutators of maximal functions, J. Math. Soc. Japan. 67, 2 (2015), 581-593.

[3] A. Almeida, J. J. Has anov, S. G. Samko, Maximal and potential operators in variable exponent Morrey spaces, Georgian Math. J. 15, 2 (2008), 195-208.

[4] J. AlvareZ AND C. PÉREZ, Estimates with $A_{\infty}$ weights for various singular integral operators, Boll. Un. Mat. Ital, A (7) 8, 1 (1994), 123-133.

[5] V. Burenkov, A. Gogatishvili, V. S. Guliyev, R. Mustafayev, Boundedness of the fractional maximal operator in local Morrey-type spaces, Complex Var. Elliptic Equ. 55, 8-10 (2010), 739-758.

[6] V. I. BuRENKov, H. V. GULIYEV, Necessary and sufficient conditions for boundedness of the maximal operator in the local Morrey-type spaces, Studia Math. 163, 2 (2004), 157-176.

[7] V. I. Burenkov, V. S. Guliyev, A. Serbetci And T. V. TARARY Kova, Necessary and sufficient conditions for the boundedness of genuine singular integral operators in local Morrey-type spaces, Dokl. Akad. Nauk 422, 1 (2008), 11-14.

[8] A. P. CALderón, Commutators of singular integral operators, Proc. Natl. Acad. Sci. USA 53 (1965), 1092-1099.

[9] A. P. CALDERón, Cauchy integrals on Lipschitz curves and related operators, Proc. Natl. Acad. Sci. USA 74, 4 (1977), 1324-1327.

[10] R. Coifman, R. RochberG, G. Weiss, Factorization theorems for Hardy spaces in several variables, Ann. of Math. 103, 2 (1976), 611-635.

[11] F. Chiarenza, M. Frasca, P. Longo, $W^{2, p}$-solvability of Dirichlet problem for nondivergence elliptic equations with VMO coefficients, Trans. Amer. Math. Soc. 336 (1993), 841-853.

[12] Y. CHEN, Regularity of solutions to elliptic equations with VMO coefficients, Acta Math. Sin. (Engl. Ser.) 20 (2004), 1103-1118.

[13] D. Cruz-Uribe, A. Fiorenza, And C. J. Neugebauer, The maximal function on variable $L_{p}$ spaces, Ann. Acad. Sci. Fenn. Math. 28 (2003), 223-238.

[14] D. Cruz-Uribe, A. Fiorenza, J. M. Martell, C. Perez, The boundedness of classical operators on variable $L^{p}$ spaces, Ann. Acad. Sci. Fenn. Math. 31 (2006), 239-264. 
[15] D. CruZ-Uribe, A. Fiorenza, Variable Lebesgue spaces: Foundations and harmonic analysis, Birkhauser/Springer, 2013. MR 3026953.

[16] F. Chiarenza, M. Frasca, Morrey spaces and Hardy-Littlewood maximal function, Rend. Math. 7 (1987), 273-279.

[17] L. Diening, Maximal functions on generalized Lebesgue spaces $L^{p(x)}$, Math. Inequal. Appl. 7, 2 (2004), 245-253.

[18] L. DiEnING, P. HARJUlehto, HäSTÖ, AND M. RUŽIČKA, Lebesgue and Sobolev spaces with variable exponents, Springer-Verlag, Lecture Notes in Mathematics, vol. 2017, Berlin, 2011.

[19] L. DIENING AND M. RÜŹIĆKA, Calderón-Zygmund operators on generalized Lebesgue spaces $L^{p(\cdot)}$ and problems related to fluid dynamics, J. Reine Angew. Math. 563 (2003), 197-220.

[20] L. Diening, P. Hasto And A. Nekvinda, Open problems in variable exponent Lebesgue and Sobolev spaces, "Function Spaces, Differential Operators and Nonlinear Analysis", Proceedings of the Conference held in Milovy, Bohemian-Moravian Uplands, May 28 -June 2, 2004, Math. Inst. Acad. Sci. Czech Republick, Praha, 2005, 38-58.

[21] G. Di Fazio And M. A. Ragusa, Commutators and Morrey spaces, Boll. Un. Mat. Ital. A (7) 5, 3 (1991), 323-332.

[22] G. Di FAZIO AND M. A. RAGUSA, Interior estimates in Morrey spaces for strong solutions to nondivergence form equations with discontinuous coefficients, J. Funct. Anal. 112 (1993), 241-256.

[23] D. FAN, S. LU AND D. YANG, Boundedness of operators in Morrey spaces on homogeneous spaces and its applications, Acta Math. Sinica (N. S.) 14 (1998), 625-634.

[24] J. Garcia-Cuerva, E. Harboure, C. Segovia, J. L. Torrea, Weighted norm inequalities for commutators of strongly singular integrals, Indiana Univ. Math. J. 40, 4 (1991), 1397-1420.

[25] V. S. Guliyev, Boundedness of the maximal, potential and singular operators in the generalized Morrey spaces, J. Inequal. Appl. Art. ID 503948, (2009), 20 pp.

[26] V. S. GuliYev, Generalized weighted Morrey spaces and higher order commutators of sublinear operators, Eurasian Math. J. 3, 3 (2012), 33-61.

[27] V. S. GuLIYEV, Local generalized Morrey spaces and singular integrals with rough kernel, Azerb. J. Math. 3, 2 (2013), 79-94.

[28] V. S. GuLIYEV, Generalized local Morrey spaces and fractional integral operators with rough kernel, J. Math. Sci. (N. Y.) 193, 2 (2013), 211-227.

[29] V. S. Guliyev, J. J. Has Anov, S. G. SAmKo, Boundedness of the maximal, potential and singular operators in the generalized variable exponent Morrey spaces, Math. Scand. 107, (2010), 285-304.

[30] V. S. GuliYev, J. J. HaS Anov, S. G. SAmko, Boundedness of the maximal, potential and singular integral operators in the generalized variable exponent Morrey type spaces $\mathscr{M}^{p(\cdot), \theta(\cdot), \omega(\cdot)}(\Omega), \mathrm{J}$. Math. Sci. (N. Y.) 170, 4 (2010), 423-443.

[31] V. S. Guliev, J. J. Has anov, S. G. SAmko, Maximal, potential and singular operators in the local “complementary" variable exponent Morrey type spaces, J. Math. Anal. Appl. 401, 1 (2013), 72-84.

[32] V. S. Guliev, S. G. S AmKo, Maximal, potential and singular operators in the generalized variable exponent Morrey spaces on unbounded sets, J. Math. Sci. (N. Y.) 193, 2 (2013), 228-248.

[33] V. S. Guliyev, T. Karaman, R. Ch. Mustafayev and A. Serbetci, Commutators of sublinear operators generated by Calderón-Zygmund operator on generalized weighted Morrey spaces, Czechoslovak Math. J. 64 (139), 2 (2014), 365-386.

[34] S. JANSON, Mean oscillation and commutators of singular integral operators, Ark. Mat. 16 (1978), 263-270.

[35] P. HëstÖ, Local-to-global results in variable exponent spaces, Math. Res. Lett. 16, 2 (2009), 263278.

[36] P. HÄstö, L. DiEnING, Muckenhoupt weights in variable exponent spaces, preprint, http://www.helsinki.fi/pharjule/varsob/publications.shtml.

[37] J. J. HASANOV, Hardy-Littlewood-Stein-Weiss inequality in the variable exponent Morrey spaces, Proc. Inst. Math. Mech. Natl. Acad. Sci. Azerb. 39 (2013), 47-62.

[38] J. J. HASANOV, Hardy-Littlewood-Stein-Weiss Inequality in the generalized Morrey spaces with variable exponent, Caspian Journal of Applied Mathematics, Ecology and Economics 2, 1 (2014), 38-59.

[39] K.-P. Ho, Vector-valued singular integral operators on Morrey type spaces and variable TriebelLizorkin-Morrey spaces, Ann. Acad. Sci. Fenn. Math. 37 (2012), 375-406.

[40] K.-P. Ho, Vector-valued operators with singular kernel and Triebel-Lizorkin-block spaces with variable exponents, Kyoto J. Math. 56 (2016), 97-124. 
[41] KwoK-Pun Ho, Singular integral operators, John-Nirenberg inequalities and Tribel-Lizorkin type spaces on weighted Lebesgue spaces with variable exponents, Revista De La Union Matematica Argentina 57, 1 (2016), 85-101.

[42] T. Karaman, V. S. Guliyev and A. Serbetci, Boundedness of sublinear operators generated by Calderón-Zygmund operators on generalized weighted Morrey spaces, An. Stiint. Univ. Al. I. Cuza Iasi. Mat. (N. S.) 60, 1 (2014), 227-244.

[43] A. KARLOVICH AND A. LERNER, Commutators of singular integrals on generalized $L^{p}$ spaces with variable exponent, Publ. Mat. 49, 1 (2005), 111-125.

[44] V. KoKILASHVILI, On a progress in the theory of integral operators in weighted Banach function spaces, "Function Spaces, Differential Operators and Nonlinear Analysis", Proceedings of the Conference held in Milovy, Bohemian-Moravian Uplands, May 28 - June 2, 2004, Math. Inst. Acad. Sci. Czech Republick, Praha, 2005, 152-175.

[45] V. KokilashVili And A. Meskhi, Boundedness of maximal and singular operators in Morrey spaces with variable exponent, Arm. J. Math. (Electronic) 1, (1) (2008), 18-28.

[46] V. Kokilashvili and S. SAmko, Singular integrals in weighted Lebesgue spaces with variable exponent, Georgian Math. J. 10, (1) (2003), 145-156.

[47] V. KoKILASHVILI AND S. SAMKO, Weighted boundedness of the maximal, singular and potential operators in variable exponent spaces, Analytic Methods of Analysis and Differential Equations, Cambridge Scientific Publishers, Eds.: A. A. Kilbas and S. V.Rogosin, 139-164, 2008.

[48] Y. KomORI AND S. SHIRAI, Weighted Morrey spaces and a singular integral operator, Math. Nachr. 282, 2 (2009), 219-231.

[49] O. Kovacik And J. Rakosnik, On spaces $L^{p(x)}$ and $W^{k, p(x)}$, Czechoslovak Math. J. 41 (116), 4 (1991), 592-618.

[50] T. S. Kopaliani, Infimal convolution and Muckenhoupt $A_{p(\cdot)}$ condition in variable $L^{p}$ spaces, Arch. Math. 89, 2 (2007), 185-192.

[51] K. Kurata, S. Nishigaki And S. Sugano, Boundedness of integral operators on generalized Morrey spaces and its application to Schrödinger operators, Proc. AMS 128, 4 (1999), 1125-1134.

[52] D. LI, G. HU, X. SHI, Weighted norm inequalities for the maximal commutators of singular integral operators, J. Math. Anal. Appl. 319, 2 (2006), 509-521.

[53] C. B. Morrey, On the solutions of quasi-linear elliptic partial differential equations, Trans. Amer. Math. Soc. 43 (1938), 126-166.

[54] T. Mizuhara, Boundedness of some classical operators on generalized Morrey spaces, Harmonic Analysis (S. Igari, Editor), ICM 90 Satellite Proceedings, Springer-Verlag, Tokyo (1991), 183-189.

[55] Y. Mizuta And T. Shimomura, Sobolev embeddings for Riesz potentials of functions in Morrey spaces of variable exponent, J. Math. Japan 60 (2008), 583-602.

[56] Y. Mizuta AND T. Shimomura, Weighted Morrey spaces of variable exponent and Riesz potentials, Math. Nachr. 288, 8-9 (2015), 984-1002.

[57] E. NAKAI, Hardy-Littlewood maximal operator, singular integral operators and Riesz potentials on generalized Morrey spaces, Math. Nachr. 166 (1994), 95-103.

[58] E. NAKAI, Generalized fractional integrals on generalized Morrey spaces, Math. Nachr. 287 (2014), 339-351.

[59] J. PeEtre, On the theory of $\mathscr{L}_{p, \lambda}$ spaces, J. Funct. Anal. 4 (1969), 71-87.

[60] S. SAmко, On a progress in the theory of Lebesgue spaces with variable exponent: maximal and singular operators, Integral Transform. Spec. Funct. 16, 5-6 (2005), 461-482.

[61] S. G. SAmko, Differentiation and integration of variable order and the spaces $L^{p(x)}$, Proceed. of Intern. Conference "Operator Theory and Complex and Hypercomplex Analysis", 12-17 December 1994, Mexico City, Mexico, Contemp. Math. 212 (1998), 203-219.

[62] Y. Sawano, D. Hakim, H. Gunawan, Non-smooth atomic decomposition for generalized OrliczMorrey spaces, Math. Nachr. 288 (2015), 1741-1775.

[63] I. I. Sharapudinov, The topology of the space $\mathscr{L}^{p(t)}([0,1])$, Mat. Zametki 26, $3-4$ (1979), 613632.

[64] Pu Zhang, Jianglong Wu, Commutators of the fractional maximal function on variable exponent Lebesgue spaces, Czechoslovak Math. J. 64 (139), 1 (2014), 183-197. 